\title{
Desenvolvimento de um protótipo de trocador de calor casco e tubo para aquecimento de caldo decantado
}

\author{
Alexsander Saves dos Santos ${ }^{1}$ \\ Douglas Almeida Teixeira ${ }^{2}$ \\ Fernanda Cristina Siqueira ${ }^{3}$
}

\begin{abstract}
RESUMO
A principal função do trocador de calor é a troca térmica entre fluidos que apresentam temperaturas opostas. Este projeto visa a produção de um trocador de calor casco e tubo para aquecer o caldo decantado de forma que o aquecimento deste caldo elimine as impurezas do processo de moagem. Através do método analítico da Média Logarítmica das Diferenças de Temperaturas (MLDT), da taxa de transferência de calor e da temperatura externa do tubo, foi possível medir com precisão a eficiência do trocador de calor, considerando que um trocador de calor de correntes opostas, nas mesmas condições de um equipamento de correntes paralelas, será sempre mais eficiente. Após o término da construção e realização de todos os testes de funcionamento e eficiência do equipamento, concluiu-se que o protótipo apresentou resultados altamente satisfatórios, atendendo aos padrões esperados.
\end{abstract}

Palavras-chave: Caldo. Protótipo. Trocador de Calor.

\footnotetext{
${ }^{1}$ Graduado em Física pelo Centro Universitário de Votuporanga - UNIFEV e em Pedagogia pela Faculdade da Aldeia de Carapicuíba - FALC. Mestre em Ciências Ambientais pela Universidade Brasil, ICESP. É professor nos Cursos de Engenharia Química e Medicina da Universidade Brasil, ICESP, Campus Fernandópolis, SP, Brasil. E-mail: saves.santos@gmail.com.

${ }^{2}$ Graduando em Engenharia Química pela Universidade Brasil, ICESP, Campus Fernandópolis, SP, Brasil. Email: douglasteixeira404@gmail.com.

${ }^{3}$ Graduanda em Engenharia Química pela Universidade Brasil, ICESP, Campus Fernandópolis, SP, Brasil. Email: fernanda.siqueira10@etec.sp.gov.br.
} 


\title{
Development of a shell and tube heat exchanger prototype for heating decanted broth
}

\begin{abstract}
The main function of the heat exchanger is the thermal exchange between fluids that have opposite temperatures. This project aims to produce a shell and tube heat exchanger for heating decanted broth so that the heating of this broth eliminates the impurities from the grinding process. Through the analytical method of the Logarithmic Mean Temperature Difference (LMTD), the heat transfer rate and the external temperature of the tube, it was possible to accurately measure the efficiency of the heat exchanger, considering that a heat exchanger of opposite currents in the same conditions as a parallel currents equipment will always be more efficient. After finishing the construction and carrying out all the tests of operation and efficiency of the equipment, it was concluded that the prototype presented highly satisfactory results, meeting the expected standards.
\end{abstract}

Keywords: Broth. Prototype. Heat Exchanger.

Artigo recebido em: 22/08/2020

Aceito em: 18/01/2021 


\section{INTRODUÇÃO}

Os primeiros protótipos de trocadores de calor foram desenvolvidos no ano de 1900 para satisfazer as necessidades das usinas de energia. Naquela época, as pesquisas se concentraram nos aspectos mecânicos e de manufatura destes equipamentos. Já nos anos de 1920 e 1930, alguns trabalhos desenvolvidos para a indústria do petróleo levaram a aprimoramentos da tecnologia. Nas duas décadas seguintes, o foco das pesquisas visou melhorias nas trocas térmicas e nos aspectos mecânicos (CAJAMARCA, 2016).

Os trocadores de calor usados pelos engenheiros químicos não podem ser caracterizados por um único modelo; e, na realidade, a variedade deste equipamento é praticamente infinita. Entretanto, uma característica comum à maior parte dos trocadores de calor é a transferência de calor de uma fase quente para uma fase fria com as duas fases separadas por uma fronteira sólida (FOUST, 2013).

De acordo com Gauto (2011) existem trocadores de calor que empregam a mistura direta dos fluidos, como, por exemplo, torres de refrigeração e aquecedores de água de alimentação. Porém, são mais comuns os trocadores nos quais os fluidos são separados por uma parede ou uma partição através da qual passa o calor.

Figura 1: Modelo de um trocador de calor casco e tubo

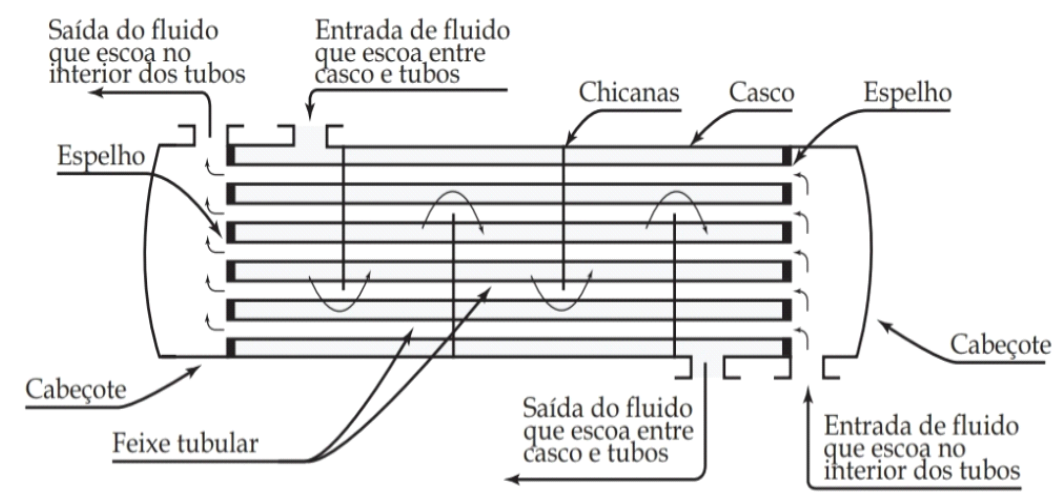

Fonte: COELHO (2016).

Segundo Coelho (2016), os trocadores de calor de casco e tubos representados na Figura 1 constituem-se de um casco, ou carcaça, contendo em seu interior um banco de tubos circular. Os tubos são presos por chicanas. Nas extremidades do equipamento, estão os cabeçotes por onde entram e saem os fluidos. Os eixos dos tubos são paralelos ao eixo do casco. Um dos fluidos passa por dentro dos tubos e o outro pelo exterior, ou seja, esse 
segundo fluido escoa pelo casco. Esses fluidos, tendo temperaturas diferentes, trocam calor entre si.

As direções dos fluidos podem ser concorrentes: o fluido que passa no interior dos tubos entra pela mesma extremidade por onde entra o fluido que passa pelo casco; ou contracorrentes: as entradas dos dois fluidos estão em extremidades diferentes (TERRON, 2012).

Segundo Foust (1982) o tipo mais simples de trocador de calor é o trocador tubular mostrado na Figura 2. Em essência, esse trocador é constituído por dois tubos concêntricos, com um dos fluidos escoando pelo tubo central enquanto o outro flui em corrente paralela ou em contracorrente no espaço anular. O comprimento de cada seção do trocador é usualmente limitado às dimensões padronizadas do tubo, de modo que é necessária uma superfície maior. Os materiais de construção são diversos, dependendo dos fluidos do processo.

Figura 2: Trocador de calor tubular

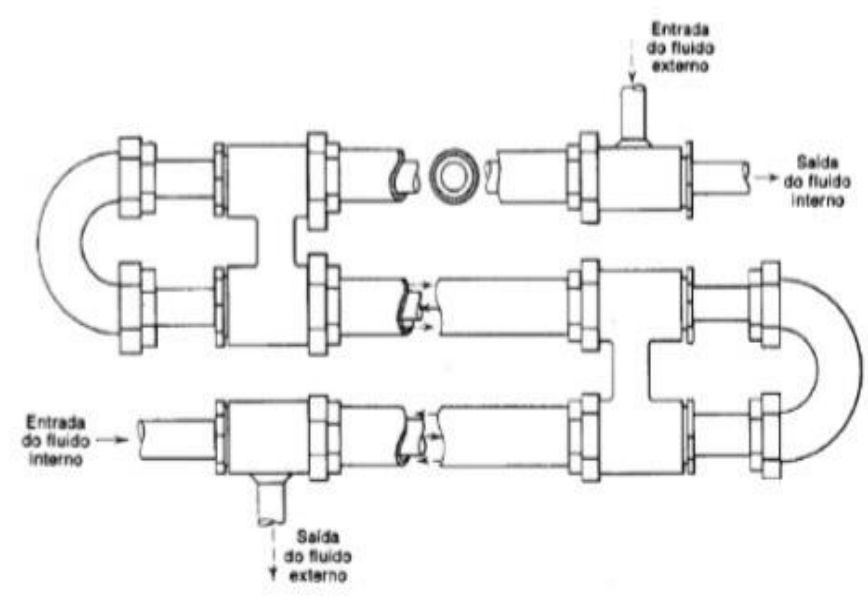

Fonte: FOUST (1982).

O trocador de placas consiste num suporte em que placas independentes do metal, sustentadas por barras, são presas por compressão entre uma extremidade móvel e outra fixa. Entre placas adjacentes formam-se canais pelos quais os fluidos escoam (GAUTO, 2011).

Para Gut (2003), o trocador de calor a placas ou PHE (do inglês, Plate Heat Exchanger), mostrado na Figura 3, consiste no escoamento dos fluidos através de canais formados entre placas metálicas sequenciais presentes no equipamento. O PHE consiste em um conjunto de placas de aço inoxidável comprimidas em um pedestal, feito de aço carbono. As placas possuem gaxetas para garantir o total isolamento dos fluidos no sistema e quatro 
orifícios de passagem de fluidos quente e frio. Esta sequência de placas com orifícios permite a formação de quatro canais paralelos, os quais, por sua vez, possibilitam a passagem alternada dos fluidos, o que possibilita a ocorrência da troca de calor deste equipamento através da superfície destas placas (WANG; SUNDÉN; MANGLIK, 2007).

Figura 3: Trocador de placas paralelas

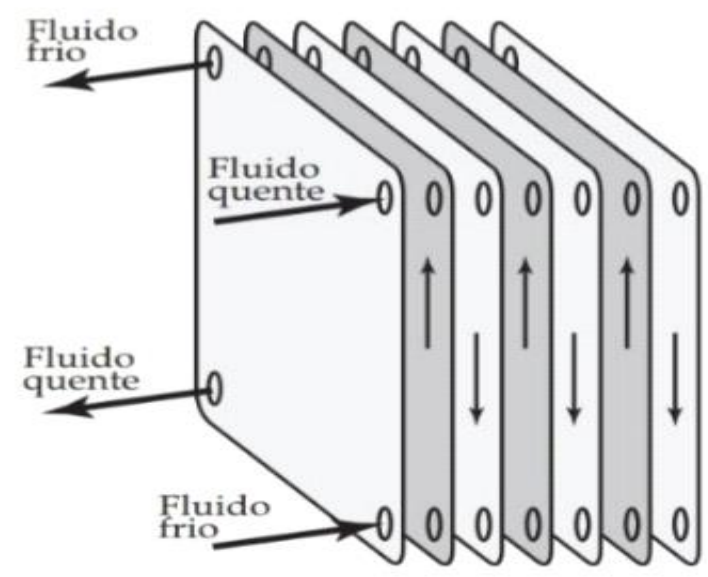

Fonte: COELHO (2016).

Uma das aplicações do trocador de calor se dá no processo de produção de açúcar, sendo utilizado na pré-evaporação do caldo decantado. Segundo Ribeiro (2003), caldo clarificado ou decantado é o caldo que saiu do decantador para eliminação das impurezas (lodo) contidas nele. A clarificação simples é o método mais antigo de purificação do caldo. Este tratamento, à base de cal e calor, forma um precipitado pesado de composição complexa, no qual parte é mais leve e parte é mais pesada do que o caldo. Esse precipitado floculante leva consigo a maior parte do material fino que está no caldo e que não foi extraído pelas peneiras no setor de moagem. A separação deste precipitado é feita por sedimentação e decantação.

Normalmente, a clarificação é atingida pelo aquecimento do caldo a aproximadamente $105^{\circ} \mathrm{C}$ e, em seguida, a adição de leite de cal para atingir um $\mathrm{pH}$ na faixa de 6,8 a 7,2. $\mathrm{O}$ caldo assim é enviado a um decantador para promover o processo de decantação. É na decantação que decorre a precipitação dos flocos formados, eliminados pelo fundo do decantador na forma de lodo. O caldo clarificado sai pela parte superior das bandejas, agora livre da maior parte das impurezas encontradas no caldo primário ou misto (GOMES, 2016). 
O tratamento do caldo fornece um caldo clarificado. Este caldo é o açúcar dissolvido na água, com certas impurezas. Como já se eliminou parte das impurezas, é preciso evaporar a água. Essa é a finalidade da evaporação (RIBEIRO, 2003).

Tendo em vista o exposto acima, este projeto visa a elaboração de um protótipo de trocador de calor casco e tubo aplicado ao aquecimento de caldo decantado para eliminação das impurezas do processo de moagem, bem como a análise de eficiência do equipamento e dos parâmetros de qualidade do caldo clarificado.

\section{METODOLOGIA}

Esse projeto foi realizado no munícipio de Fernandópolis-SP, sendo baseado no sistema operacional da Usina Coruripe S/A, filial de Carneirinho-MG, situada na fazenda Bom Sucesso S/N.

A pesquisa desenvolvida foi experimental de natureza qualiquantitativa, em que se buscou reproduzir um protótipo, em menor escala, do trocador de calor, utilizado na usina, para o aquecimento do caldo decantado. A Figura 4 mostra as etapas do desenvolvimento do protótipo.

Figura 4: Etapas do desenvolvimento do projeto

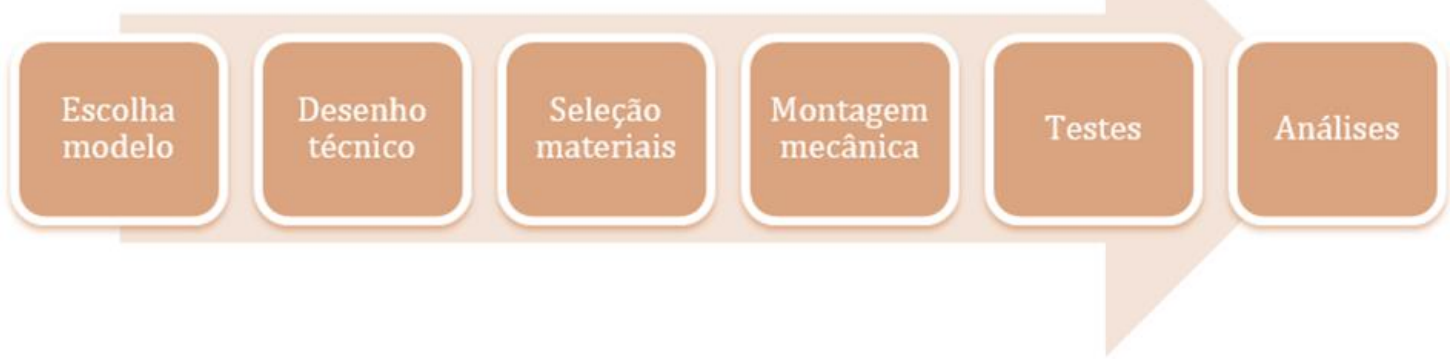

Fonte: Autoria própria.

\subsection{Montagem do trocador de calor}

Os materiais utilizados para a confecção do trocador foram adquiridos através de doações da referida usina e por meio de recursos próprios, conforme a Tabela 1. 
Tabela 1: Materiais utilizados para confecção do trocador de calor

\begin{tabular}{|c|c|c|c|c|}
\hline Nome do Material & Quantidade & Unidade & Vr. unitário (R\$) & Vr. total $(R \$)$ \\
\hline Acrílico & 0,565 & $\mathrm{~m}^{2}$ & 0,00 & $\mathbf{0 , 0 0}$ \\
\hline Broca $6,35 \mathrm{~m}$ & 2 & un & 9,20 & 18,40 \\
\hline Chapa 3mm & 0,565 & $\mathrm{~m}^{2}$ & 0,00 & $\mathbf{0 , 0 0}$ \\
\hline Cola de Vedação & 90 & $\mathrm{~g}$ & 0,00 & $\mathbf{0 , 0 0}$ \\
\hline Cotovelo $1 / 2, '$ PVC & 5 & un & 0,86 & 4,30 \\
\hline Curva 1 1/2,", & 6 & un & 0,00 & $\mathbf{0 , 0 0}$ \\
\hline Eletrodo inox 309 & 3 & $\mathrm{~kg}$ & 0,00 & $\mathbf{0 , 0 0}$ \\
\hline Luva $1 / 2$, PVC & 2 & un & 0,60 & 1,20 \\
\hline Parafuso $12 \mathrm{~mm}$ & 12 & un & 0,00 & $\mathbf{0 , 0 0}$ \\
\hline Termômetro & 4 & un & 25,135 & 100,54 \\
\hline $\begin{array}{l}\text { Tinta Spray Metálica Alta } \\
\text { Temperatura }\end{array}$ & 0,9 & $\mathrm{~L}$ & 18,50 & 18,50 \\
\hline Tubo $1 / 2, ’$ PVC & 1 & $\mathrm{~m}$ & 5,20 & 5,20 \\
\hline Tubo 1/1/2," & 1,2 & $\mathrm{~m}$ & 0,00 & $\mathbf{0 , 0 0}$ \\
\hline Tubo 6" inox & 1 & $\mathrm{~m}$ & 0,00 & $\mathbf{0 , 0 0}$ \\
\hline Tubo Cobre 6,35m & 18 & $\mathrm{~m}$ & 8,88 & 160,00 \\
\hline Válvula $1 / 2$ " inox & 1 & un & 9,40 & $\mathbf{9 , 4 0}$ \\
\hline Válvula $1 / 2$ " PVC & 2 & un & 6,00 & 12,00 \\
\hline Válvula 11/2,' & 1 & un & 19,20 & 19,20 \\
\hline TOTAL & & & & 348,74 \\
\hline
\end{tabular}

Fonte: Autoria própria.

Para o início da construção, utilizou-se 60 tubos para fabricação do feixe tubular do trocador de calor, calculado pela Equação 1:

$$
n=\frac{A_{e}}{2 \cdot \pi \cdot r_{e} \cdot L}
$$

onde, $n$ é o número de tubos, $A_{e}$ é a área necessária, $r_{e}$ é o raio externo dos tubos e $L$ é o comprimento.

Através de $18 \mathrm{~m}$ de tubos de cobre com 6,35 mm de diâmetro foram realizados cortes com 295 mm de comprimento para confecção do feixe tubular. Elaboraram-se os cortes de $2 \mathrm{~m}$ de tubo com $32 \mathrm{~mm}$ de diâmetro para fazer a entrada do fluido quente no trocador de calor. 
Com a posse dos materiais, realizou-se um corte em um tubo de inox de $145 \mathrm{~mm}$ de diâmetro com $350 \mathrm{~mm}$ de comprimento. Em seguida, foi realizado um novo corte em 3 chapas de $3 \mathrm{~mm}$ com $145 \mathrm{~mm}$ de diâmetro e, com a utilização de uma broca de 6,35 mm, fez-se uma perfuração no espelho. Houve a divisão das chicanas e a soldagem dos espelhos nas extremidades do tubo.

Os tubos de cobre foram inseridos na perfuração do espelho, no qual foi feito anteriormente o mandrilhamento dos tubos para evitar a mistura dos fluidos. Cortou-se um flange de $145 \mathrm{~mm}$ de diâmetro para fazer o fechamento do equipamento.

Realizou-se um corte em uma chapa de $35 \mathrm{~mm}$ para fazer a separação do trocador de calor em 6 passes. O acrílico, com $160 \mathrm{~mm}$ de diâmetro, foi cortado para fabricação da tampa do equipamento e proporcionar visibilidade das etapas de passagem do fluido frio. Fez-se as instalações das conexões de entrada e saída do fluido frio e instalada a tubulação de 1 1/2" que conduzirá o fluido quente até o equipamento.

Uma nova instalação de uma válvula de $11 / 2$ " foi efetuada para fazer o bloqueio do fluido quente e controle da temperatura e, assim, inseriu-se a lira de dilatação e condensação do vapor gerado. Executou-se o acoplamento da caldeira para o reservatório de água e ocorreu a instalação de termômetros nas entradas e saídas dos fluídos quente e frio.

Por fim, foi feita a pintura do equipamento e, assim, finalizada a montagem do trocador, conforme mostra a Figura 5.

Figura 5: Trocador finalizado

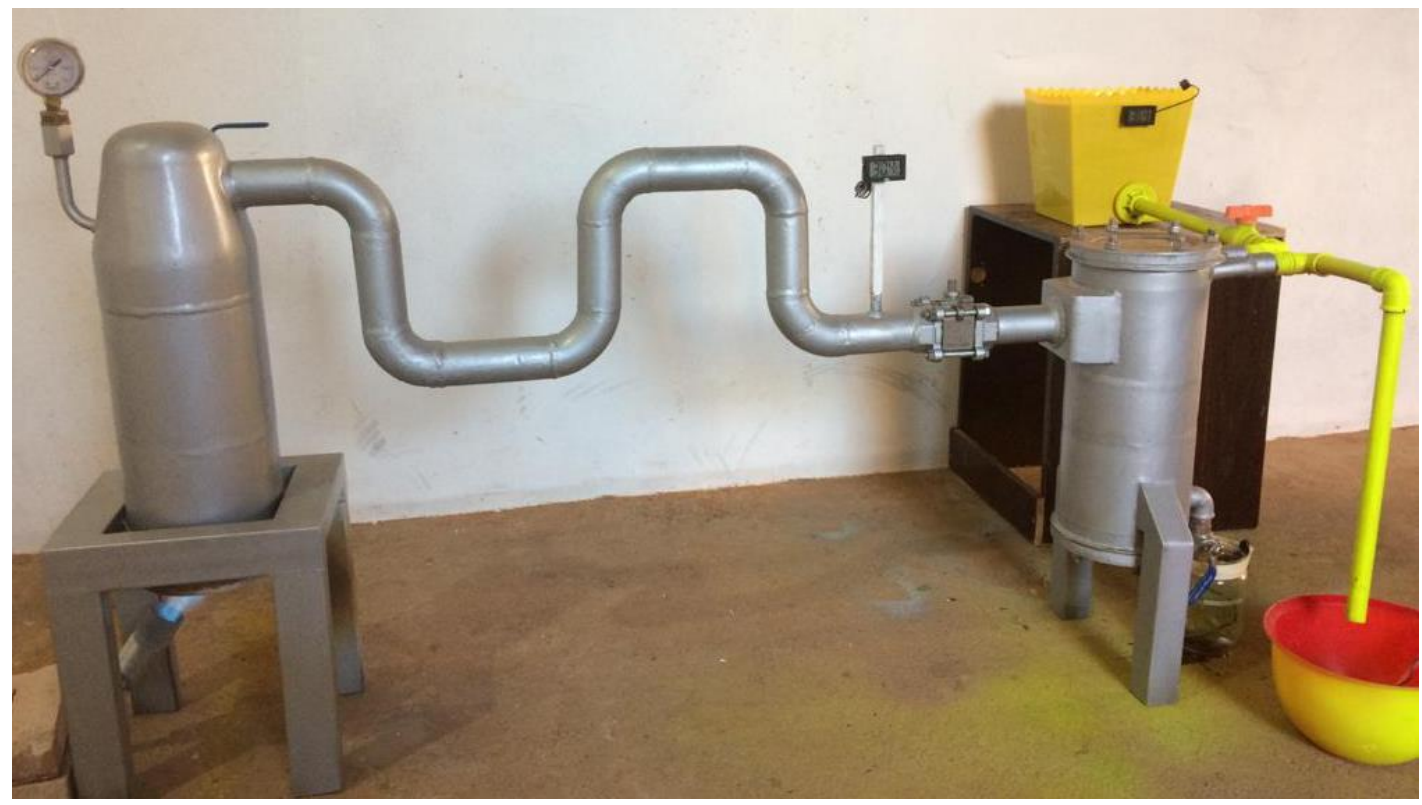

Fonte: Autoria própria. 


\subsection{Teste de desempenho do trocador de calor}

Os testes foram realizados na cidade de Carneirinho - MG. Iniciaram-se os testes colocando o caldo decantado no reservatório onde houve a medição da temperatura. Foi aberta a válvula de alívio da caldeira e colocado 4 L de água. Ligou-se o fogareiro para iniciar o aquecimento da água e, em seguida, realizou-se a medição da temperatura dela.

Após o aquecimento, a válvula do controle de vazão do fluido foi aberta para dar início a circulação dentro dos tubos do trocador. Depois do início da circulação, realizou-se a abertura da válvula de controle da vazão e aguardou-se o preenchimento total de todos os tubos com o caldo decantado.

Após o preenchimento do fluido frio (caldo decantado) e com sua saída, regulou-se a vazão do fluido para aproximadamente $0,45 \mathrm{~L} / \mathrm{min}$ com auxílio de uma proveta de $1 \mathrm{~L}$ e de um cronômetro, realizando o aquecimento gradativo do caldo decantado até a estabilização de sua temperatura final.

A temperatura do fluido quente foi medida após a troca térmica, antes da saída do trocador, que foi realizada pela parte inferior dele.

\subsection{Cálculo da eficiência do trocador de calor}

Com o intuito de analisar a eficiência da máquina, foi realizado o cálculo da MLDT (Média Logarítmica das Diferenças de Temperaturas) para descobrir a eficiência do trocador. Utilizou-se a Equação 2, que representa um trocador que opera em correntes opostas, ou contracorrente:

$$
M L D T=\frac{\Delta T_{\text {máxima }}-\Delta T_{\text {mínima }}}{\ln \left(\frac{\Delta T_{\text {máxima }}}{\Delta T_{\text {mínima }}}\right)}
$$

onde, $\Delta T_{\text {máxima }}$ é a variação de temperatura máxima, calculada pela subtração entre a temperatura de entrada do fluído quente com a temperatura de saída do fluído frio e $\Delta T_{\text {mínima }}$ é a variação de temperatura mínima, calculada pela subtração da temperatura de saída ou descarga do fluído quente, com a temperatura de entrada do fluído frio. 


\subsection{Cálculo da transferência de calor e da temperatura da superfície externa}

A transferência de calor, segundo Foust et al. (2013), se faz pelo contato de uma fase quente e uma fase fria por intermédio de uma fronteira bem definida de acordo com a prática industrial (Figura 6).

Figura 6: Condições de temperatura num trocador de calor

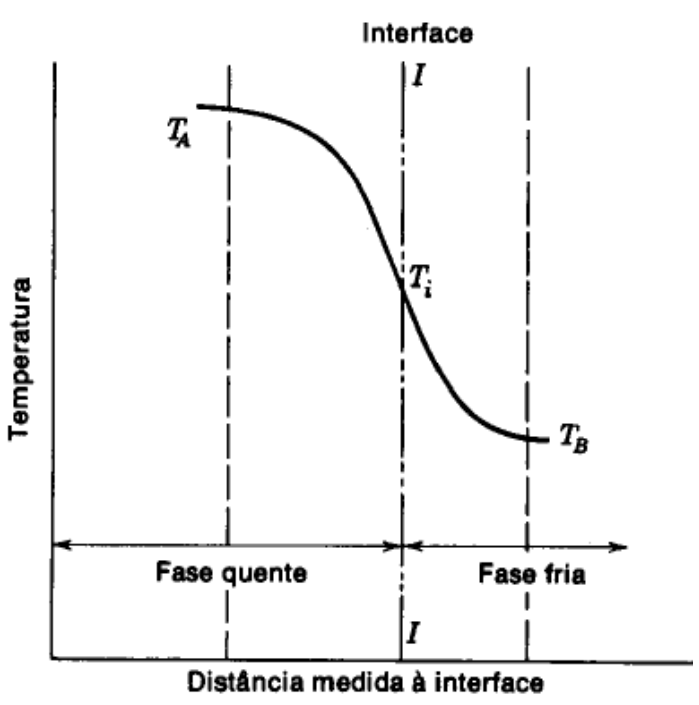

Fonte: Foust et al. (2013).

A transferência de calor termodinâmica e mecânica é calculada com o coeficiente de transferência de calor, a proporcionalidade entre o fluxo de calor e a força motriz termodinâmica para o fluxo de calor. O fluxo de calor é uma representação vetorial quantitativa de calor através de uma superfície (NORMAN LONEY, 2010).

Para encontrar a força motriz total, considerando as temperaturas num certo ponto do trocador de calor, utilizou-se a Equação 3:

$$
\Delta T=T_{B}-T_{A}
$$

onde, $\Delta T$ é a força motriz das temperaturas em ${ }^{\circ} \mathrm{C}, T_{A}$ e $T_{B}$ são as temperaturas nas fases quente e fria, respectivamente.

Encontrou-se a área de transferência de calor da fase quente e fria e, em seguida, a área média dessas áreas. Utilizou-se neste processo a Equação 4:

$$
A=\pi D L
$$


onde, $A$ é a área de transferência de calor, $D$ é o diâmetro do tubo e $L$ é o comprimento do tubo.

Para o cálculo da taxa de transferência de calor no trocador utilizaram-se as Equações 5 e 6 :

$$
\begin{gathered}
\frac{1}{U A}=\frac{1}{h_{A} A_{A}}+\frac{\Delta x}{k A_{m e ́ d}}+\frac{1}{h_{B} A_{B}} \\
q=\frac{-\Delta T}{\frac{1}{U A}}
\end{gathered}
$$

onde, $\mathrm{U}$ é coeficiente global de transmissão de calor em W/m²-K; $A_{A}$ e $A_{B}$ são as áreas de transferência em m² nas fases quente e fria, respectivamente; $h_{A}$ e $h_{B}$ são os coeficientes de transmissão de calor em W/m ${ }^{2}-\mathrm{K}$ das fases quente e fria, respectivamente; $\Delta \mathrm{x}$ é a espessura do tubo em m; $\mathrm{k}$ é a condutividade térmica do tubo em W/m-K; q é a taxa de transferência de calor em $\mathrm{J} / \mathrm{s}$; e $\Delta \mathrm{T}$ é a força motriz das temperaturas em ${ }^{\circ} \mathrm{C}$.

A fim de confirmar o desempenho do trocador de calor, utilizou-se a Equação 7 para o calcular a temperatura da superfície externa do tubo:

$$
q=\frac{\Delta T}{R}
$$

onde, q é a taxa de transferência de calor em $\mathrm{J} / \mathrm{s}, \Delta T$ é a força motriz das temperaturas em ${ }^{\circ} \mathrm{C}$ e $R$ é a resistência térmica.

\subsection{Cálculo do desvio padrão}

Com intuito de validar os resultados da eficiência do trocador de calor, calculou-se o desvio padrão com a Equação 8:

$$
\sigma=\sqrt{\sum_{i=1}^{n} \frac{\left(x_{1}-M_{A}\right)^{2}}{n}}
$$

onde, $\sigma$ é o desvio padrão, $M_{A}$ é a média dos valores, $x_{1}$ valor individual, $n$ sendo a quantidade de dados. 


\subsection{Análise da qualidade do caldo clarificado}

Inicialmente, coletou-se $6 \mathrm{~L}$ de caldo decantado. Calibrou-se o equipamento com duas gotas de água destilada para depois dar início a análise com auxílio de uma pipeta de Pasteur. Coletou-se uma pequena porção do caldo, e foram levadas ao refratômetro algumas gotas do caldo para análise do BRIX.

Para análise de pH, inicialmente, fez-se a limpeza do eletrodo. Realizou-se a calibração do pHmetro com as soluções tampão de pH 4.0 e pH 10.0 e a solução tampão neutra de pH 7.0. Uma pequena porção de caldo decantado foi colocada no béquer de $50 \mathrm{ml}$, e após foi realizada medida com o pHmetro.

\section{RESULTADOS E DISCUSSÃO}

A Tabela 2 apresenta os resultados obtidos através dos testes, do valor da MLDT, e das temperaturas, tanto de entrada (E) quanto de saída (S) dos fluídos quentes (TQ) e frios (TF) em ${ }^{\circ} \mathrm{C}$. Como pode ser observado, o teste 3 foi o que apresentou maior eficácia, já que, quanto maior o valor da MLDT, melhor é o desempenho da troca térmica do trocador de calor.

Tabela 2: Resultados dos testes do trocador de calor

\begin{tabular}{c|ccccc} 
Teste & TQ, E $\left({ }^{\circ} \mathbf{C}\right)$ & $\mathbf{T F}, \mathbf{E}\left({ }^{\circ} \mathbf{c}\right)$ & $\mathbf{T Q}, \mathbf{S}\left({ }^{\circ} \mathbf{C}\right)$ & $\mathbf{T F}, \mathbf{S}\left({ }^{\circ} \mathbf{C}\right)$ & MLDT \\
\hline 1 & 93,4 & 36,0 & 52,7 & 76,1 & $\mathbf{1 6 , 9}$ \\
2 & 91,8 & 36,7 & 48,4 & 71,0 & $\mathbf{1 5 , 8}$ \\
3 & 92,5 & 36,2 & 51,8 & 72,3 & $\mathbf{1 7 , 8}$
\end{tabular}

Fonte: Autoria própria.

Ao realizar os testes, foi mensurada a vazão volumétrica de saída do caldo que foi aquecido, obtendo-se um valor de 0,45 L/min. A Tabela 3 apresenta a comparação do teste 3 com o teste realizado por Chaves et al. (2015), mostrando que o protótipo apresentou maior eficiência. Como pode ser observado, a vazão volumétrica da literatura é maior que a do protótipo. Vale ressaltar também que ambos os fluídos do trocador comparativo são água. 
Tabela 3: Comparativo entre trocadores de calor (Protótipo X Literatura)

\begin{tabular}{|c|cccccc|}
\multicolumn{2}{|c}{$\begin{array}{c}\text { VAZÃO } \\
\text { VOLUMÉTRICA } \\
\text { (L/MIN) }\end{array}$} & $\begin{array}{c}\text { TQ,E } \\
\left({ }^{\circ} \mathbf{C}\right)\end{array}$ & $\begin{array}{c}\text { TF,E } \\
\left({ }^{\circ} \mathbf{C}\right)\end{array}$ & $\begin{array}{c}\text { TQ,S } \\
\left({ }^{\circ} \mathbf{C}\right)\end{array}$ & $\begin{array}{c}\text { TF,E } \\
\left({ }^{\circ} \mathbf{C}\right)\end{array}$ & MLDT \\
\hline LITERATURA & 1,50 & 50,1 & 24,6 & 47,1 & 28,4 & $\mathbf{2 2 , 1}$ \\
PROTÓTIPO & 0,45 & 92,5 & 36,2 & 51,8 & 72,3 & $\mathbf{1 7 , 8}$ \\
\end{tabular}

Fonte: Autoria própria.

Após a realização dos cálculos da taxa de transferência de calor e da temperatura da superfície externa do tubo, obteve-se os seguintes resultados como mostra a Tabela 4. Observa-se que em todos os testes os resultados ficaram bem próximos; e que o Teste 1 apresentou melhor transferência de calor no equipamento.

Tabela 4: Taxa de transferência de calor e da temperatura da superfície externa do tubo

\begin{tabular}{c|ccc|} 
PARÂMETROS & TESTE 1 & TESTE 2 & TESTE 3 \\
\hline $\boldsymbol{q}(\mathrm{J} / \mathrm{S})$ & 412,95 & 395,4 & 405,04 \\
$\mathrm{~T}_{2}\left({ }^{\circ} \mathrm{C}\right)$ & 52,105 & 53,76 & 52,896 \\
\hline
\end{tabular}

Fonte: Autoria própria.

Segundo Callegaro (2014) o desvio padrão máximo, quando $n$ é igual a 3, deve ser 1,38 ; e o utilizado no projeto obteve 0,810 , comprovando que o protótipo atende às expectativas.

Para evidenciar a qualidade do caldo clarificado, foram realizadas algumas análises de Brix. Seus resultados representam a porcentagem em massa de sólidos solúveis, importantes para a indústria sucroalcooleira para a formação dos cristais de açúcar. Segundo Ribeiro (2003), a concentração ideal do Brix após o trocador de calor deve ser em média de $20^{\circ}$ e as análises realizadas geraram um Brix no valor de $13,18^{\circ}$. Para ocorrer a cristalização, é necessário um Brix de $78^{\circ}$ a $80^{\circ}$. Ainda, segundo Ribeiro (2003), a análise de pH é importante para que as perdas de sacarose por inversão permaneçam num nível mínimo durante o processo subsequente à recuperação de açúcar. Sendo assim, o pH ideal deve ficar em torno de 6,5, e as análises resultaram em um pH de 6,95. 


\section{CONCLUSÃO}

A troca térmica é o processo de transferência de calor de um corpo para outro, o equipamento de troca térmica é utilizado na usina para o aquecimento do caldo decantado.

O objetivo da elaboração de um protótipo de trocador de calor casco e tubo foi produzir um equipamento que atendesse às necessidades específicas de troca térmica em menor escala, fazendo-o funcionar corretamente, conforme valores de referência da literatura. Observa-se que o protótipo operou adequadamente, sendo eficiente para a realização da troca térmica, conforme os cálculos realizados e comparados com a literatura, visto que foram obtidos valores próximos mesmo trabalhando com fluidos e vazões diferentes.

\section{REFERÊNCIAS}

CAJAMARCA, S. P. A. Análise teórica de trocadores de calor casco - casco termossifões. 2016. 151 p. Dissertação (Mestrado em Engenharia Mecânica) Universidade Federal de Santa Catarina, Florianópolis, 2016. Disponível em: https://repositorio.ufsc.br/xmlui/bitstream/handle/123456789/172354/343115.pdf?sequenc $\mathrm{e}=1 \&$ isAllowed=y. Acesso em: 24 maio 2020.

CALLEGARO, R. F. Uma arquitetura para fusão de dados de sensores de baixo custo em redes de sensores sem fio. 2014. 134 p. Dissertação (Mestrado em Engenharia de Automação e Sistemas) - Centro Tecnológico, Universidade Federal de Santa Catarina, 2014.

Disponível

em: https://repositorio.ufsc.br/xmlui/bitstream/handle/123456789/129459/327790.pdf?sequenc e=1\&isAllowed=y. Acesso em: 3 dez. 2020.

CHAVES, F. J. F. et al. Análise Técnica da Eficiência de um Trocador de Calor do Tipo Casco-Tubos. In: V Encontro Regional de Química \& IV Encontro Nacional de Química, 2015, São Paulo. Anais [...]. Blucher Chemistry Proceedings, v. 3, 2015, p. 905-914. Disponível em: http://pdf.blucher.com.br.s3-sa-east1.amazonaws.com/chemistryproceedings/5erq4enq/eng3.pdf. Acesso em: 3 dez. 2020.

FOUST, A. S.; WENZEL, L. A.; CLUMP, C. W.; MAUS, L.; ANDERSON, L. B. Princípio das operações unitárias. Rio de janeiro: LTC, 1982.

GAUTO, M. A.; ROSA. G. R. Processos e operações unitárias da indústria química. Rio de Janeiro: Ciência Moderna, 2011.

GOMES, Wellington. Processo de Tratamento de Caldo em Usinas Sucroalcooleiras. LinkedIn. 2016. Disponível em: https://www.linkedin.com/pulse/processo-de-tratamentocaldo-em\%20usinas-wellington-gomes/. Acesso em: 26 maio 2020. 
GUT, J. A. W. Configurações ótimas para trocadores de calor a placas. 2003. 244 p. Tese (Doutorado em Engenharia) - Escola Politécnica, Universidade de São Paulo, 2003. Disponível em: https://www.teses.usp.br/teses/disponiveis/3/3137/tde-22102003093322/publico/Tese_Jorge_A_W_Gut.pdf. Acesso em: 3 dez. 2020.

RIBEIRO, P. R. A Usina de Açúcar e sua Automação. Araçatuba: Smar, 2003.

TERRON, L. R. Operações unitárias para químicos, farmacêuticos e engenheiros fundamentos e operações unitárias. Rio de Janeiro: LTC, 2012.

WANG, L.; SUNDÉN, B.; MANGLIK, R. M. Plate Heat Exchangers: Design, Applications and performance. Boston: WIT Press, 2007. 